\title{
Development of undergraduate family medicine teaching in China
}

\section{INTRODUCTION}

China is the most highly-populated country in the world with increasing demand for health care. ${ }^{1}$ Family medicine can improve health care in China, and can supply good health outcomes, equitably and economically.

Family medicine education in China currently exists in three models - resident training, on-the-job training, and undergraduate teaching ${ }^{2}$ - but only undergraduate teaching may provide more competent family physicians in China. ${ }^{1} \mathrm{~A}$ general description of undergraduate family medicine teaching in the last two decades is lacking and to determine the situation in China we sent a questionnaire to every Chinese medical school enquiring about family medicine teaching and analysed the results.

Family medicine teaching has undergone several milestones in China. ${ }^{3}$ In 1992, the undergraduate family medicine teaching programme was initiated in the Capital Medical University in Beijing. In November 1993, family medicine was recognised as a new academic discipline by the Chinese Medical Association. The Chinese Society of General Practice was founded in 1995. In 1999, 'Directives on Chinese family medicine education' was issued by the Ministry of Health. ${ }^{4}$ In 2006, the Chinese government adopted new strategies for the development of family medicine teaching and community health service. ${ }^{3}$ Over the last two decades, the number of medical schools with family medicine teaching has significantly increased. Whether the quantity was compatible and well distributed was not known. We decided to investigate the number, growth, and variation of family medicine teaching across Chinese medical schools. Also, most importantly, we investigated whether there was any difference between the 'advanced' and 'wealthy' regions of China, and the poorer hinterland.

In developed countries such as the UK, a family medicine teaching curriculum has been well supported in undergraduate training. ${ }^{5}$ But how well has it been supported in China?

\section{METHOD}

In March 16, 2009 a questionnaire was sent to 128 official medical schools all over China. The programme directors in family medicine were invited to complete questionnaires. This study was approved by The Chinese Family Medicine Education Directive Committee of Ministry of Education.

\section{RESULTS}

\section{Response rate}

All 128 medical schools in China sent back the completed questionnaire in time. The response rate was $100 \%$.

\section{Growth of family medicine units in undergraduate programmes in the past two decades}

The first family medicine course was introduced in a medical school in 1992 but there was no growth in number until 1995. The number increased slowly from 1995 to 1996 with a growth of two and one respectively. From 1997 to 2008 , a total of 55 medical schools began to include family medicine as part of the undergraduate curriculum, with an average growth rate of 13.75 schools every 3 years. This growth was 16 in 2000-2002, 14 in 2003-2005, and 14 in 2006-2008.

\section{Undergraduate teaching programmes in different regions}

China has very different levels of economic development and medical services per region. ${ }^{6}$ As economic development has a strong impact on educational level, ${ }^{7}$ we scored for very underdeveloped regions (GDP pre capita $\leq \$ 3000)$, underdeveloped regions (GDP pre capita $>\$ 3000$ and $\leq \$ 5000)$ and relatively developed regions (GDP pre capita > \$5000). .,9 $^{8}$

The relationship between the economic status and the number of medical schools with undergraduate family medicine education in mainland China is shown in Table 1.

\section{Course arrangement and hosted department}

In addition, throughout China different approaches to developing undergraduate family medicine teaching are taken (Table 2).

\section{DISCUSSION}

\section{A need for continuous growth of} family medicine teaching in medical schools

Family medicine teaching in Chinese medical schools has changed very significantly in the last decade, expanding from zero to 59 schools. However, family medicine teaching in undergraduate medicine may not be enough to meet the demand for family medicine in such a highly-populated country.

Chinese policy on family medicine now plays an important role in developing family medicine teaching in Chinese medical schools. ${ }^{4}$ Before 1996, the Chinese government seldom provided any directions to encourage teaching on family medicine, which led to slow growth in that period. However, the China Ministry of Health and nine other ministries decided to develop urban community health service after 1996, which resulted in a rapid growth of family medicine teaching in medical schools. The government's emphasis on family medicine can be revealed by the policy document and stated directives. In 2009, the Chinese State Council established community health centre systems and designated three family physicians per 10000 people on average all over the country in the near future. ${ }^{10}$ It also supported family medicine education through a series of policies that encouraged medical schools and affiliated hospitals to train up more family physicians. ${ }^{10}$

China requires a continuous growth of family medicine education in medical schools to provide more family physicians serving the primary care needs of the community and to deliver comprehensive, 
Table 1. Numbers of medical schools in different regions.

\begin{tabular}{lccc} 
Region & $\begin{array}{c}\text { Total number } \\
\text { of provinces }\end{array}$ & $\begin{array}{c}\text { Total number of } \\
\text { medical schools }\end{array}$ & $\begin{array}{c}\text { Schools with } \\
\text { family medicine } \\
\text { teaching } n(\%)\end{array}$ \\
\hline GDP pre capita $\leq \$ 3000$ & 20 & 72 & $30(41.7)$ \\
\hline $\begin{array}{l}\text { GDP pre capita } \\
>\$ 3000 \text { and } \leq \$ 5000\end{array}$ & 6 & 31 & $14(45.2)$ \\
\hline GDP pre capita $>\$ 5000$ & 5 & 25 & $15(60.0)$ \\
\hline Total & 31 & 128 & $59(46.1)$ \\
\hline
\end{tabular}

Table 2. Family medicine course arrangement and hosted unit.

\begin{tabular}{lcc} 
Hosted unit & Schools, $n(\%)$ & $\begin{array}{c}\text { Schools incorporated clinical } \\
\text { exposure practice into the curriculum, } n(\%)\end{array}$ \\
\hline Family medicine & $27(45.8)$ & $10(16.9)$ \\
\hline Public health & $11(18.6)$ & $3(5.08)$ \\
\hline Internal medicine & $3(5.08)$ & $1(1.69)$ \\
\hline Social medicine & $2(3.89)$ & $1(1.69)$ \\
\hline Health management & $4(6.78)$ & 0 \\
\hline Others & $12(20.3)$ & $3(5.08)$ \\
\hline Total & $59(100)$ & $18(30.5)$
\end{tabular}

continuous, holistic, and person-centered care.

\section{The mismatch with local need}

This investigation showed that family medicine teaching in undergraduate level was not well-distributed in different regions in China associated with economic levels. Therefore, the government should pay more attention to the underdeveloped regions and support development of family medicine teaching in these regions.

\section{Greater need for practice sessions in the curriculum}

Curriculum family medicine education in medical schools includes lecture sessions and practice sessions. Our study demonstrates that Chinese medical schools lacked practice sessions.

Furthermore, there was a lack of standardised objectives and teaching content of family medicine in the academic sessions and the monitoring system on the teaching quality and feedback evaluation. Although the concept and principles of family medicine are well introduced in each of the 59 medical schools, other important topics are not incorporated in undergraduate family medicine teaching, such as 'chronic disease management in family medicine' and 'life period care'. This may be the result of a lack of experienced teaching staff and/or well designed teaching material.

\section{The undertaking of family medicine teaching requires a uniform model} Our further investigation of the teaching organisation of family medicine showed that the programme was confusing and was introduced inconsistently in different medical schools. In some schools, the family medicine curriculum was incorporated into the base medical unit or social unit. It is well known that family medicine undergraduate teaching in developed countries is mostly run by the clinic medical department or family medicine unit. ${ }^{11}$ For example, there are established family medicine departments in Estonia, Slovenia, Poland, and the Czech Republic. ${ }^{11}$

In Hong Kong, there are also established family medicine units in The Chinese University of Hong Kong and Hong Kong University and their teaching has been well utilised by the affiliated hospital. ${ }^{12}$ The reason why family medicine is partially undertaken by public health units in China requires further investigation. One of the explanations is that family medicine was first introduced in China by teachers from the public health department. ${ }^{4}$
A 'whole person care' and 'holistic model' of family care can be delivered well in China but there needs to be cooperation between clinical medicine and public health. In the future, family medicine undergraduate education can also be hosted by family medicine units as well as other clinical units including public health units. However, the way to establish a more structured undergraduate family medicine teaching still needs to be discussed and implemented.

\section{Yafang Huang and Aimin Guo}

School of Public Health and Family Medicine, Capital Medical University, Beijing, 100069, China.

\section{Funding}

The research was funded by the Beijing Municipal Commission of Education.

\section{Editorial Note}

First motion - China is a founder member of human civility and society. Discuss.

Second motion - China deserves good primary care.

\section{REFERENCES}

1. Nieman LZ, Kvale PJ, Fu X, et al. Bringing a family medicine model of health to the People's Republic of China. Fam Med 2001; 33: 696-701.

2. Yang J, Guo A, Wang Y, et al. Human resource staffing and service functions of community health services organizations in China. Ann Fam Med 2008; 6: 421-427.

3. Chen T, Du Y, Sohal A, Underwood M. Family medicine education and training in China: past, present and future. Br J Gen Pract 2007; 57: 674-676.

4. Meng Q, Xie J, Wu P, et al. Status quo and reflection of general practice training in China. Chinese Gen Pract 2006; 9: 175-176.

5. Hooper J, Dowell AC, Kinnersley P. Academic departments of general practice at the crossroads? $\mathrm{Br} J$ Gen Pract 1990; 40: 268-269.

6. Wang H, Xu T, Xu J. Factors Contributing to high costs and inequality in China's health care system. JAMA 2007; 298: 1928-1930.

7. Li H. Huang L. Health, education, and economic growth in China: empirical findings and implications. China Economic Review 2008; 5: 16-25.

8. National Bureau of Statistics of China. China population census. http://www.stats.gov.cn/tjgb/rkpcgb/ (accessed 10 Mar 2011).

9. National Bureau of Statistics of China. China economic census. http://www.stats.gov.cn/zg)jpc/cgfb/ (accessed 10 Mar 2011).

10. Shen Q, Yang J, Huang Y, et al. A study on status of health human resources in community health service institutions in Beijing. Chinese Gen Pract 2009; 12(23): 2169-2172.

11. Bohumil S, Igor S, Tiik M, et al. Perspectives of family medicine in Central and Eastern Europe. Fam Pract 2008; 25(2): 113-118.

12. Tai-fai FOK. Medical education in Hong Kong — past, present, and future. The Hong Kong Medical Diary 2009; 14(8): 6-8.

DOI: 10.3399/bjgp11X568134 